\title{
Helical chirality induction of expanded porphyrin analogues
}

\author{
JUN-ICHIRO SETSUNE \\ Department of Chemistry, Graduate School of Science, Kobe University, Nada-ku, Kobe 657 8501, Japan \\ e-mail: setsunej@kobe-u.ac.jp
}

\begin{abstract}
Expanded porphyrin analogues with unique figure-eight conformation were prepared by way of useful pyrrole intermediates such as bis(azafulvene)s and 2-borylpyrrole. Supramolecular chirogenesis of cyclooctapyrrole $\mathbf{O 1}$ with $32 \pi$-cycloconjugation was successfully applied to determine absolute configuration of chiral carboxylic acids. Dinuclear $\mathrm{Cu}^{\mathrm{II}}$ complex of cyclooctapyrrole $\mathbf{O 2}$ with interrupted $\pi$-conjugation was resolved by HPLC into enantiomers and their helical handedness was determined by theoretical simulation of their CD spectral pattern. Enantioselective induction of helicity in the metal helicate formation in the presence of a chiral promoter was demonstrated by using $(R)-(+)-1-(1-$ phenyl)ethylamine that favoured $P, P$ helicity. Dinuclear $\mathrm{Co}^{\mathrm{II}}$ complexes of cyclotetrapyrroletetrapyridine $\mathbf{O 3}$ were found to be substitution labile and pick up amino acid anions in water. Those amino acid complexes of $\mathbf{O 3 C \mathbf { C o } _ { 2 }}$ were rendered to adopt a particular unidirectional helical conformation preferentially depending on the ligated amino acid anion.
\end{abstract}

Keywords. Porphyrin analogues; metal complexes; helical chirality; chirality sensing.

\section{Introduction}

Chemistry of expanded porphyrins has made great progress in the last couple of decades. ${ }^{1}$ Novel structures, properties, and reactions have been reported. The figure-eight conformation as evidenced by X-ray crystal structures of [40]decaphyrin(1.0.1.0.0.1.0.1.0.0), [32] octaphyrin(1.0.1.0.1.0.1.0), [34]octaphyrin(1.1.1.0.1.1.1.0), and [36]octaphyrin(2.1.0.1.2.1.0.1) in the mid 90's is one of the most intriguing aspects of expanded porphyrins. $^{2,3}$ Topological feature of the double half twist of this figure-eight conformation in relation to the number of $\pi$-electrons attracts much attention in the context of aromaticity and antiaromaticity. ${ }^{4}$ On the other hand, helical chirality originated from figure-eight conformation of cyclooctapyrroles was demonstrated by Vogel. ${ }^{5}$ That is, HPLC separation of [36]octaphyrin(2.1.0.1. 2.1.0.1) on a chiral phase was successful to determine helical handedness of the Pd complex by X-ray crystallography. The relationship between the helical handedness of the free base [36] octaphyrin(2.1.0.1.2.1.0.1) and the chiroptical feature has recently been unambiguously determined by the theoretical study. ${ }^{6}$ Since the electronic circular dichroism arising from the chromophore of porphyrins and the related compounds is a powerful tool for studying chiral materials, porphyrins have been frequently utilized in chiral sensing and memory. ${ }^{7,8}$ For example, complexation with chiral ligands induced the bisporphyrin tweezer to take a particular conformation with an excess of unidirectional screw between the two porphyrin moieties. ${ }^{7 \mathrm{a}-\mathrm{d}}$ In this context, application of cyclooctapyrroles with a figure-eight conformation to chirality sensing and asymmetric catalysis is of great interest. To this end, we have been interested in developing properly designed expanded porphyrin analogues O1, O2, and $\mathbf{O 3}$ to be applied for inducing helical chirality (chart 1).

\section{Synthesis}

\subsection{Synthesis by way of bis(azafulvene)}

Connecting two pyrrole units is a fundamental reaction in the porphyrinoid synthesis and there are two major such reactions to form dipyrrylmethene units 1; that as in the Rothemund type reaction from pyrrole and aldehyde (route A-D) and that as in the MacDonald-[2+2] type reaction from dipyrrylmethane and dipyrrylmethane-5,5'-dialdehyde (route B) in scheme 1.9,10 The latter generates stable dipyrrylmethane $\mathbf{1}$ directly by acid catalysed dehydration but strongly acidic reaction conditions are usually employed, while the former uses drastic reaction conditions to make in situ oxidation of the initially formed dipyrrylmethane $\mathbf{2}$. Since dipyrrylmethane and water under acidic conditions proceed to fragmentation as a backward reaction, relatively low efficiency and scrambling of the pyrrole units in the product macrocycles become problematic. Lindsey improved these situations by using two-step, one-flask, room-temperature procedure (route A-D). ${ }^{11}$ That is, dipyrrylmethane formation 

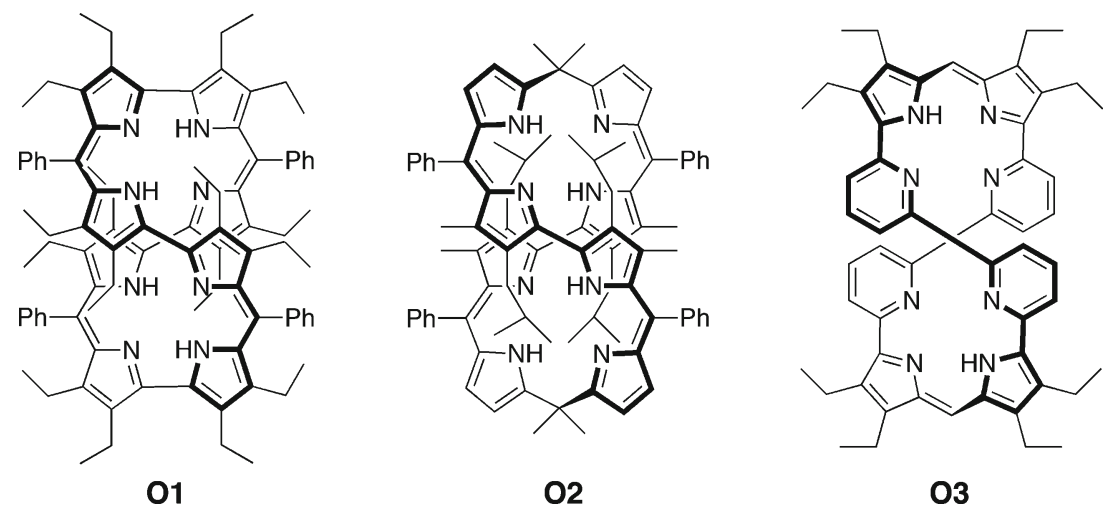

Chart 1. Expanded porphyrin analogues with figure-eight conformation.

using low reactant concentration in $\mathrm{CH}_{2} \mathrm{Cl}_{2}$ followed by addition of oxidizing agent such as 2,3-dichloro-5,6dicyano-1,4-benzoquinone (DDQ). Pyrrole-2-carbinol 3 can be a good starting material that is really an intermediate in the reaction of pyrrole and aldehyde of route A. Although Lindsey procedure starting from 3 was successfully applied for regioselective [2+2]-type porphyrin synthesis (route C-D), the generated water still causes undesired results in some cases.

We have found that $\mathbf{3}$ itself is cleanly dehydrated by the reaction with $(\mathrm{Boc})_{2} \mathrm{O}$ in the presence of DMAP to give isolable azafulvene 4 in good yield. ${ }^{12}$ It turned out that $\mathbf{4}$ was reactive enough to act as Michael type acceptor when reacted with $\alpha$-free pyrrole at room temperature in the absence of acid catalyst (route E-D). The reaction of $\mathbf{4}$ with pyrrole is not dehydration but addition and can be performed under neutral conditions. Therefore, acid-catalysed fragmentation-cyclization sequence responsible for the redistribution equilibrium among cyclooligomers of different ring size to favour thermodynamically more stable small ones as shown in scheme 2 is not occurring in the synthesis of porphyrinoids. This azafulvene methodology is suitable for the preparation of large sized porphyrinoids.
Two examples of synthesis of porphyrin analogues are shown in schemes 3 and 4 where bis(azafulvene) 5 and bis(azafulvenyl)dimethylmethane $\mathbf{6}$ were successfully used under neutral conditions. VilsmeierHaack aroylation followed by $\mathrm{NaBH}_{4}$ reduction according to the Lindsey protocol gave 2,2'-bipyrrole-5, $5^{\prime}$-di(arylcarbinol) in good yield and then it was cleanly converted to bis(azafulvene) $\mathbf{5}$ as shown in scheme 3 . When 5 was reacted with the parent 2,2-bipyrrole at room temperature and then with DDQ, a mixture of porphyrinoid homologues with $8,12,16,20$, and 24 pyrrole units was isolated in $22,3,4,3$, and $2 \%$ yield, respectively. ${ }^{13}$ Since this reaction does not generate homologues having $6,10,14,18$, and 22 pyrrole units, separation of the products mixture is much easier than those derived from TFA-catalysed condensation of 2,2'-bipyrrole and benzaldehyde where cyclohexapyrrole and cyclooctapyrrole $\mathbf{O 1}$ are the only isolable products. ${ }^{14}$

An alternative method to get such dipyrrole5,5'dicarbinols is Vilsmeier-Haack formylation followed by addition of aryllithium as shown in scheme 4 . The resulting gem-dimethyl-2,2'-dipyrrylmethane-5,5'di(arylcarbinol) was converted to bis(azafulvene) 6.

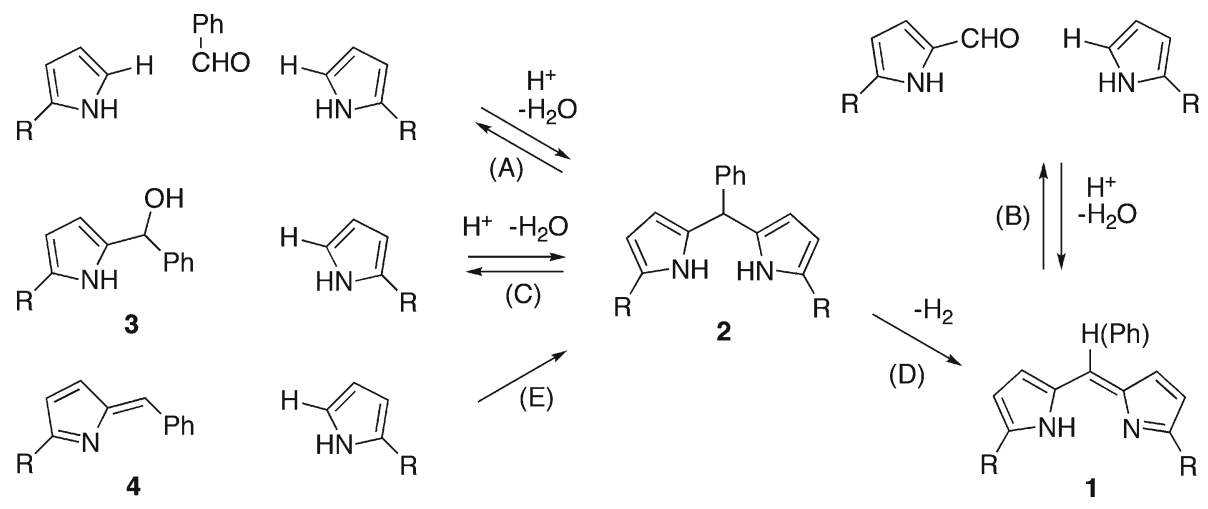

Scheme 1. Azafulvene 4 as a useful precursor for connecting pyrrole units in the synthesis of porphyrinoids. 
$\left\langle\mathrm{N}_{\mathrm{H}}\right\rangle+\mathrm{PhCHO} \stackrel{\mathrm{H}^{+}-\mathrm{H}_{2} \mathrm{O}}{\rightleftarrows}$

Scheme 2. Acid-catalysed fragmentation-cyclization sequence in the porphyrin synthesis.

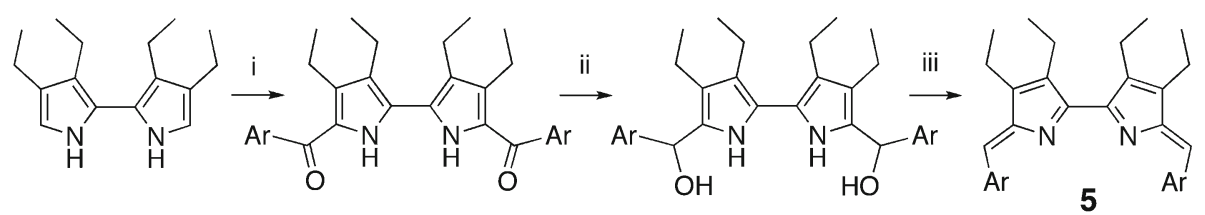

i) $\mathrm{ArCONMe}_{2}, \mathrm{POCl}_{3}(\mathrm{Y}=70-90 \%)$; ii) $\mathrm{NaBH}_{4}(\mathrm{Y}=80-90 \%)$; iii) (Boc) $)_{2} \mathrm{O}$, DMAP ( $\left.\mathrm{Y}=80-90 \%\right)$. $\mathrm{Ar}=\mathrm{C}_{6} \mathrm{H}_{5}, \mathrm{C}_{6} \mathrm{H}_{4}-p-\mathrm{NO}_{2}, \mathrm{C}_{6} \mathrm{H}_{4}-p-\mathrm{OMe}$<smiles>CCc1c(-c2ccccc2)[nH]c(-c2ccccc2)c1CC</smiles>

1) r.t, $1 \mathrm{~h}$

2) $D D Q(3$ eq)

$+\quad \frac{3) \mathrm{OH}^{-}}{\mathrm{CH}_{2} \mathrm{Cl}_{2}}$<smiles>CCc1c[nH]c(-c2[nH]cc(CC)c2CC)c1CC</smiles>

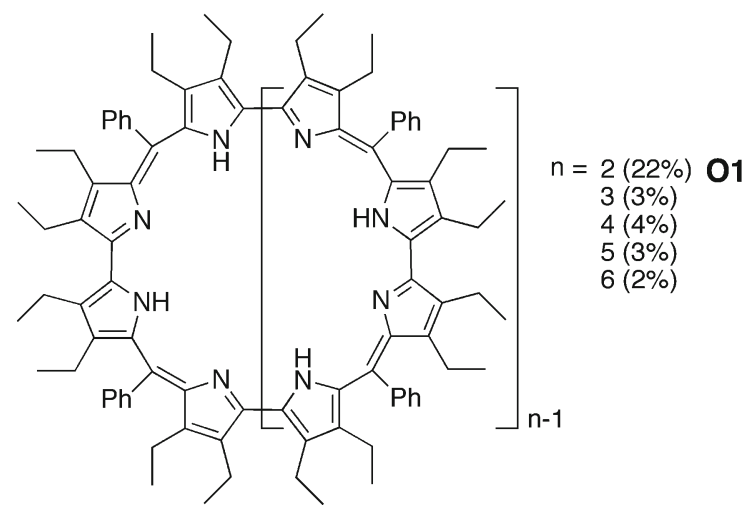

Scheme 3. Synthesis of expanded porphyrins using bis(azafulvene) 5.
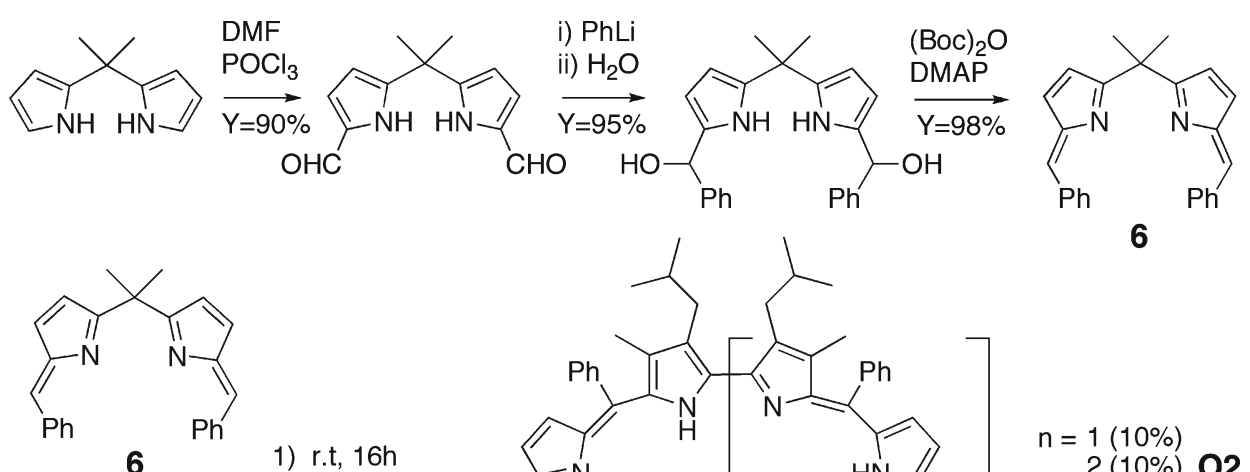

1) r.t, $16 \mathrm{~h}$

2) $\mathrm{DDQ}(3 \mathrm{eq})$

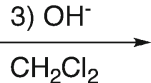

$\sum_{H}$

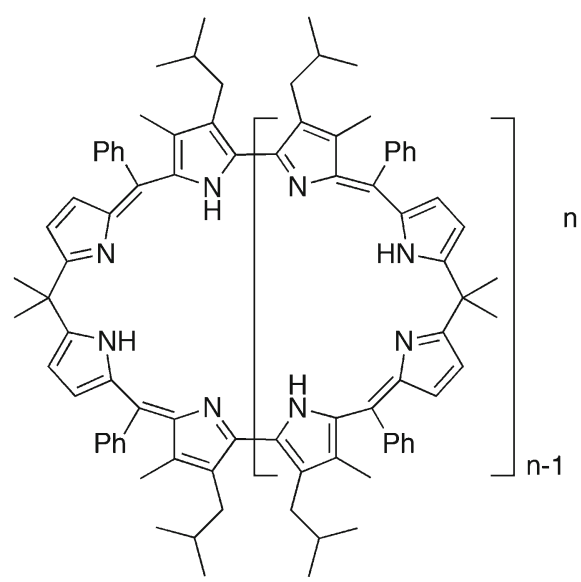

6

Scheme 4. Synthesis of expanded porphyrins using bis(azafulvene) 6 . 
Then, 6 was allowed to react with 2,2'-bipyrrole to generate a mixture of porphyrinoid homologues with different ring sizes from cyclotetrapyrrole to cyclooctacosapyrrole after DDQ oxidation. ${ }^{15} \mathrm{Up}$ to cyclotetratetracontapyrrole having 44 pyrrole units was separated by GPC and characterized by mass analysis in this reaction and macrocycles having scrambled arrangements of two components was not detected. This cyclooctapyrrole $\mathbf{O 2}$ has two parts of $\pi$-conjugated tetrapyrrole chromophores are connected by $\mathrm{sp}^{3}$ carbons.

\subsection{Synthesis by way of 2-borylpyrrole}

Development of new building blocks is of great importance to make porphyrin analogues with unique structure and property. Dipyrrylarenes are potential candidate for making larger macrocycles because the rigid structure having direct connection of pyrrole rings with an arene ring would not reduce cyclization efficiency as compared to 2,2'-bipyrrole. Furthermore, photo, redox, and acid-base functionality intrinsic to the arene moiety can be introduced into the macrocycle. In this context, we have prepared 2-borylpyrrole 7 quantitatively according to the protocol for borylation of aromatic halides starting from 2-carboethoxy-3,4-dialkylpyrrole that is readily obtainable by Barton-Zard pyrrole synthesis. ${ }^{16}$ 2-Borylpyrrole was used successfully for coupling with various commercially available aromatic dihalides in the Suzuki-Miyaura cross coupling reactions as shown in scheme $5 .{ }^{17}$ 6,6'-Di-(2-pyrryl)$2,2^{\prime}$-Bipyridine was readily obtained from $6,6^{\prime}$ dibromo-2,2'-bipyridine and then used for synthesizing cyclotetrapyrroletetrapyridine $\mathbf{0 3}{ }^{18}$

\section{Helical chirality induction}

\subsection{Chirality sensing of carboxylic acids by $\mathbf{O 1}$}

Facile methods for the determination of molecular chirality are of increasing interest in view of the role of chirality in natural phenomena and medicine. Based on the circular dichroism (CD) exciton chirality method, the supramolecular chirality induction has been successfully used for the absolute configuration determination of chiral substances. ${ }^{7 \mathrm{a}-\mathrm{d}}$ The unique structure of cyclooctapyrroles is potentially effective in sensing wide spectrum of chiral substances. X-ray crystallography of $\mathrm{O1}$ indicates figure-eight conformation that leads to a $P, P$ helical enantiomer and a $M, M$ helical enantiomer (figure 1). $\mathbf{O 1}$ is undergoing rapid inversion<smiles>CCOC(=O)c1[nH]c(I)c(CC)c1CC</smiles><smiles>CCOC(=O)c1[nH]c(B2OC(C)(C)C(C)(C)O2)c(CC)c1CC</smiles>
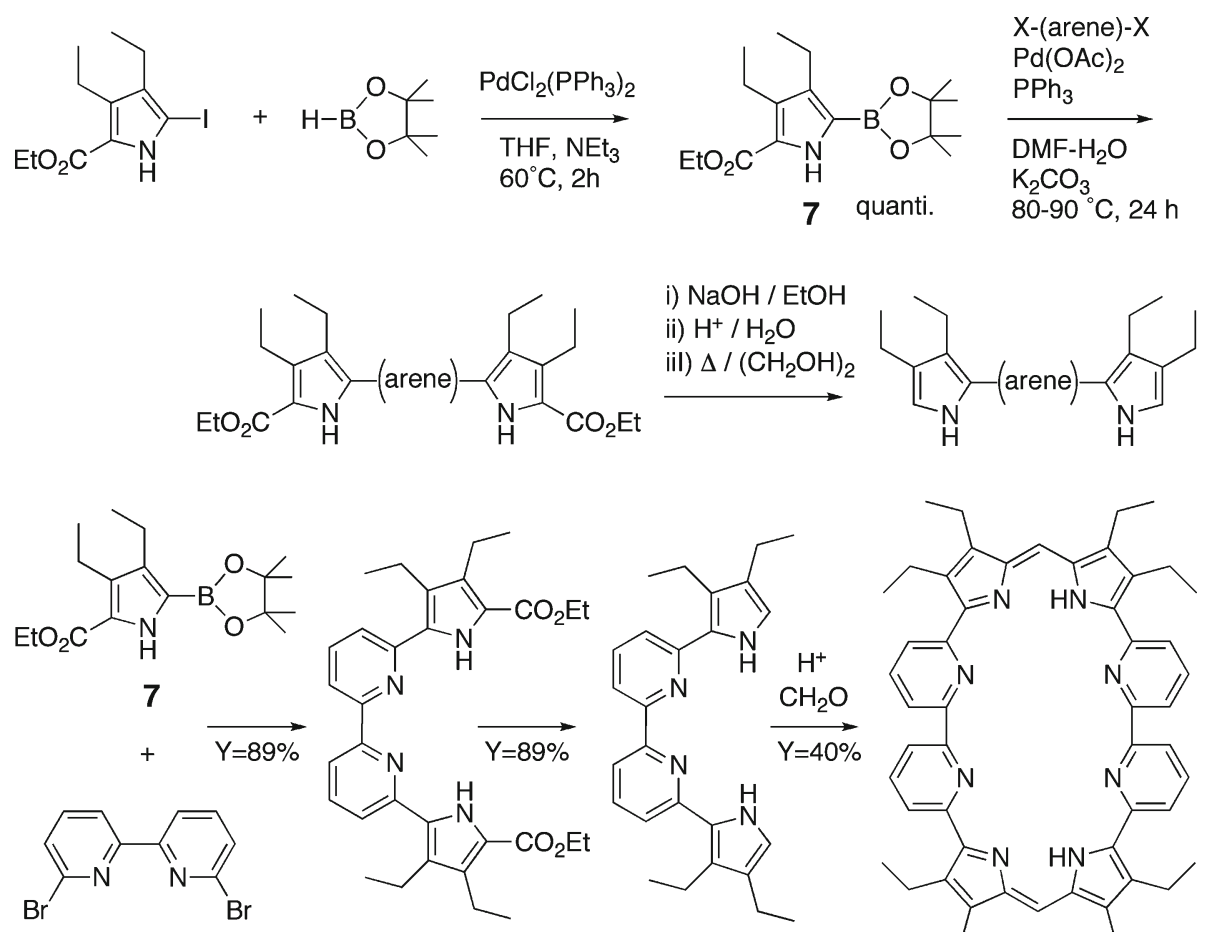

Scheme 5. Synthesis of dipyrrylarenes by using borylpyrrole 7 and their application to the porphyrin analogue $\mathbf{O 3}$. 

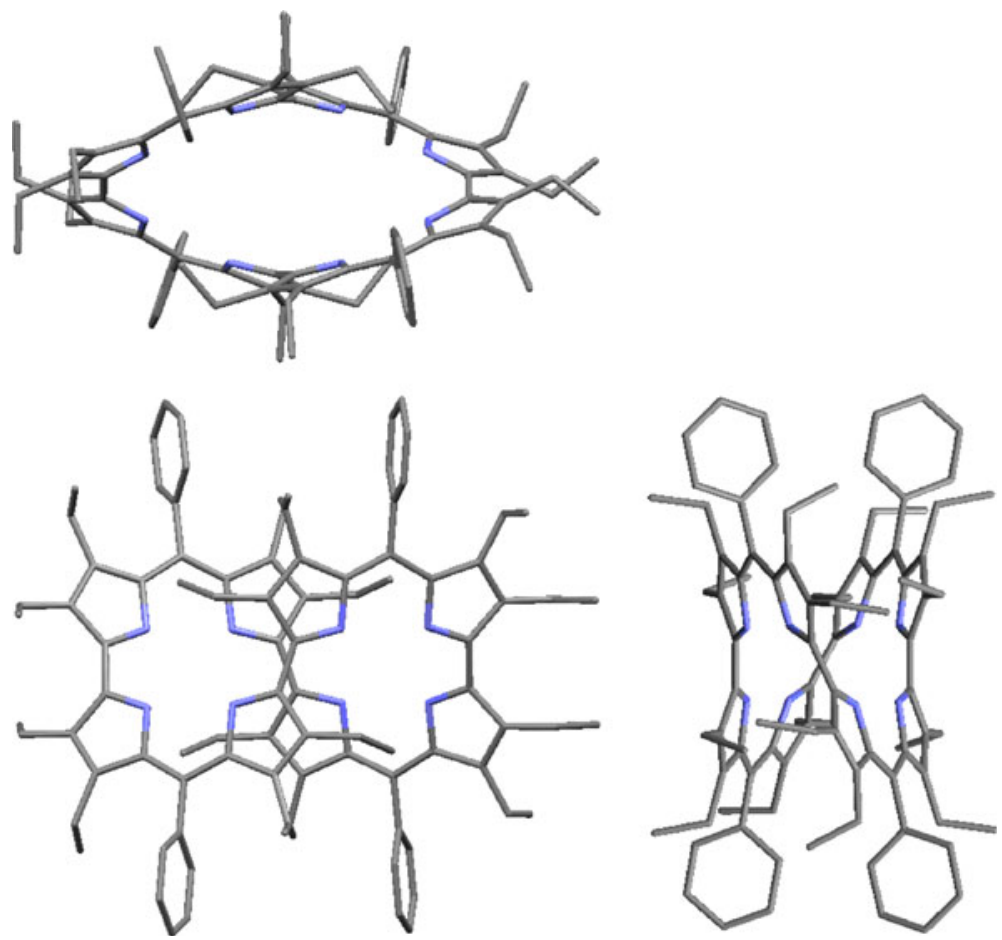

Figure 1. X-ray diagram of $\mathbf{O 1}$ viewed along right axes.

between the $M, M$ form and the $P, P$ form in solution. ${ }^{19}$ The $\mathrm{CD}$ spectrum is silent for $\mathbf{O 1}$, whereas the positive $1^{\text {st }}$ Cotton effect of the bisignate $C D$ signal band at $644 \mathrm{~nm}$ arises upon complexation with $(R)-(-)$ mandelic acid. ${ }^{20}$ The titration experiment shows that the CD band at $644 \mathrm{~nm}$ and the UV-vis band at $647 \mathrm{~nm}$ due to both $1: 1$ and $1: 2$ complexes take the maximum intensity at 50 equiv of $(R)-(-)$-mandelic acid (figure 2a,b). The sign of this induced Cotton effect is solely determined by the absolute configuration of the carboxylic acid thus $(S)-(+)$-mandelic acid induced a mirror image $\mathrm{CD}$ spectrum. The ability of sensing the chirality of carboxylic acids by $\mathbf{O 1}$ is remarkable. All the $(S)$-configuration acids examined induce nega- tive and the $(R)$-acids positive chirality (table 1$)$. The OH group containing acids, A1-A3, make complete conversion of $\mathbf{O 1}$ to diprotonated species that give clear CD spectra when added 300-fold excess. Also, the positioning of the $1^{\text {st }}$ Cotton effect and UV-vis absorption maxima are similar. The lactic acid derivative A4 and the $\mathrm{CF}_{3}$ group containing $\mathbf{A 1 1}$ bind strongly to $\mathbf{0 1}$ and easily form tri- and tetraprotonated complexes that show characteristic UV-vis absorption band at around $590 \mathrm{~nm}$ when present more than 30 molar equivalents. Weak binding was observed for simple carboxylic acids, A6-A8. This is most likely due to their less acidic nature in comparison with the $\alpha$-hydroxyl acids, A1A4. Although 3-phenyllactic acid A4 binds much more
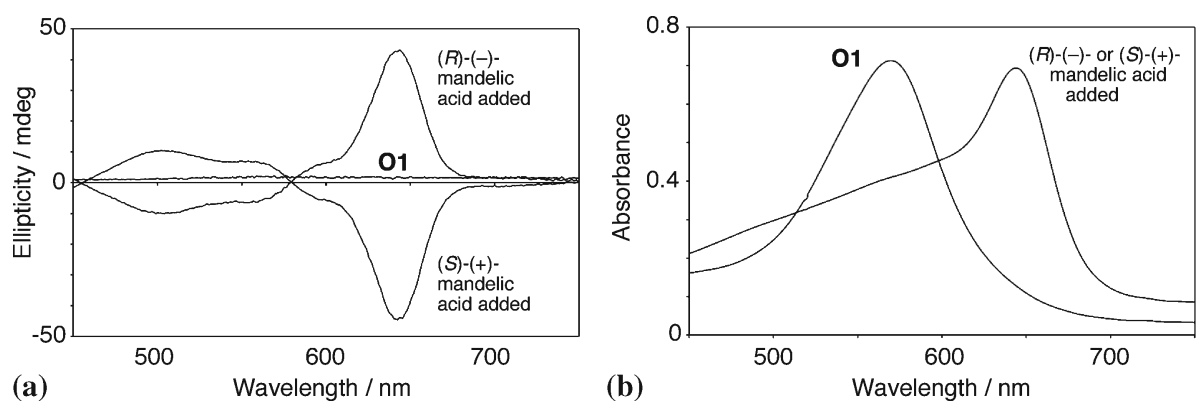

Figure 2. $\mathrm{CD}$ (a) and UV-vis (b) spectral changes of $\mathbf{O 1}\left(5.9 \mu \mathrm{M}\right.$ in $\left.\mathrm{CH}_{2} \mathrm{Cl}_{2}\right)$ upon addition of $(R)-(-)$ - or $(S)-(+)$-mandelic acid $(18 \mathrm{mM}$ in $\mathrm{MeOH})$ at $293 \mathrm{~K}$. 
Table 1. CD and UV-vis spectrometric data for supramolecular chirogenesis upon complexation of $\mathbf{O 1}$ with various chiral carboxylic acids at $298 \mathrm{~K}$ in a $1 \mathrm{~cm}$ optical cell. ${ }^{[a]}$

\begin{tabular}{|c|c|c|c|}
\hline Ligand & $\begin{array}{l}\text { CD sign }\left(\lambda_{\max } / n m\right) \\
\text { of } 1^{\text {st }} \text { Cotton effect }\end{array}$ & $\begin{array}{c}\text { UV-vis } \\
\left(\lambda_{\max } / \mathrm{nm}\right)\end{array}$ & $\begin{array}{l}\Delta \theta / \Delta \mathrm{abs} \\
(\mathrm{mdeg})^{[\mathrm{f}]}\end{array}$ \\
\hline$(R)-(-)-\mathbf{A} \mathbf{1}^{[\mathrm{b}]}$ & $+(644)$ & 647 & 87 \\
\hline$(S)-(+)-\mathbf{A} 1^{[b]}$ & $-(644)$ & 647 & 81 \\
\hline$(R)-(-)-\mathbf{A} 2^{[\mathrm{b}]}$ & $+(639)$ & 649 & 55 \\
\hline$(S)-(+)-\mathbf{A} 2^{[\mathrm{b}]}$ & $-(639)$ & 649 & 49 \\
\hline$(S)-(-)-\mathbf{A} 3^{[b]}$ & $-(642)$ & 647 & 60 \\
\hline$(S)-(-)-\mathbf{A} 4^{[\mathrm{b}, \mathrm{d}]}$ & $-(644)$ & 636 & 17 \\
\hline$(S)-(-)-\mathbf{A} 5^{[\mathrm{b}]}$ & $-(611)$ & 638 & 11 \\
\hline$(R)-(-)-\mathbf{A} 6^{[\mathrm{c}]}$ & $+(642)$ & 642 & 21 \\
\hline$(S)-(+)-\mathbf{A} 6^{[\mathrm{c}]}$ & $-(642)$ & 642 & 27 \\
\hline$(S)-(+)-\mathbf{A} 7^{[\mathrm{b}, \mathrm{e}]}$ & $-(644)$ & 636 & 26 \\
\hline$(S)-(+)-\mathbf{A} 8^{[\mathrm{c}, \mathrm{e}]}$ & $-(641)$ & 641 & 6 \\
\hline L-A9 ${ }^{[b]}$ & $-(643)$ & 646 & 17 \\
\hline$(S)-(-)-\mathbf{A} 10^{[\mathrm{c}, \mathrm{e}]}$ & $-(622)$ & 630 & 12 \\
\hline$(R)-(+)-\mathbf{A 1 1} 1^{[\mathrm{c}, \mathrm{d}]}$ & $+(647)$ & 642 & 19 \\
\hline$(S)-(-)-\mathbf{A} 11^{[\mathrm{c}, \mathrm{d}]}$ & $-(647)$ & 642 & 15 \\
\hline
\end{tabular}

[a] $[\mathrm{O1}]=6.5 \mu \mathrm{M}$ in $\mathrm{CH}_{2} \mathrm{Cl}_{2}$. [carboxylic acid] $=1.95 \mathrm{mM}$. ${ }^{\text {bb] }}$ in $\mathrm{MeOH}$. ${ }^{[\mathrm{c}]}$ in $\mathrm{CH}_{2} \mathrm{Cl}_{2}$. ${ }^{[\mathrm{d}]} \mathrm{C}=195 \mu \mathrm{M}$. ${ }^{\text {ee] }} \mathrm{C}=9.75 \mathrm{mM} .{ }^{[\mathrm{ff}]} \mid 1^{\text {st }}$ Cotton effect $\lambda_{\max } \mathrm{mdeg} / /$ corresponding band $\lambda_{\max } \Delta$ abs<smiles>O=C(O)C(O)c1ccccc1</smiles>

A1<smiles>O=C(O)C(O)C1CCCCC1</smiles>

A2<smiles>CC(C)CC(O)C(=O)O</smiles>

A3<smiles>O=C(O)C(O)Cc1ccccc1</smiles>

A4<smiles>CC(Br)C(=O)O</smiles>

2-bromopropionic acid A5<smiles>CC(C(=O)O)c1ccccc1</smiles><smiles>[124In]</smiles>
propionic acid A6<smiles>COc1ccc2cc(C(C)C(=O)O)ccc2c1</smiles>

2-(6-methoxynaphth-2-yl)propionic acid

A7<smiles>O=C(O)CC(NC(=O)O)C(=O)OC(=O)O</smiles>

N-Boc-aspartic acid A9<smiles>C=C(C)C1CC=C(C(=O)O)CC1</smiles>

A10<smiles>CCC(C)C(=O)O</smiles>

A8<smiles>COC(C(=O)O)(c1ccccc1)C(F)(F)F</smiles>

$\alpha$-methoxy- $\alpha$-trifluoromethylphenylacetic acid

A11 strongly than 2-hydroxyisocaproic acid A3 but yields smaller intensity CD spectrum, which is consistent with the substituent bulkiness order effect. The large size of the naphthyl derivative substituent in $\mathbf{A 7}$ is a possible reason for the weak binding thus suggesting that $\mathbf{O 1}$ is not able to complex with even larger size carboxylic acids. Surprisingly, the absolute configuration of the remote chiral centre in $\mathbf{A 1 0}$ can be read out by O1. This dynamic helical chirality induction depends on the relative thermodynamic stability of two diastereomeric complexes, for example, $(S)-(+)$-mandelic acid complex of $M, M$ heliccal $\mathbf{O 1}$ and $(S)-(+)$-mandelic acid complex of $P, P$ heliccal $\mathbf{O 1}$ as shown in scheme 6.

\subsection{Enantioselective helical chirality induction}

Helical chirality is usually controlled by introducing a chiral auxiliary to cause the generation of a particular helical form in diastereomeric excess as described for 01. ${ }^{21}$ However, enantioselective induction of helicate formation with a chiral promoter in the absence of homochiral auxiliary is a challenging research target. $\mathbf{O 2}$ was readily metallated by $\mathrm{Cu}(\mathrm{OAc})_{2}$ to give 


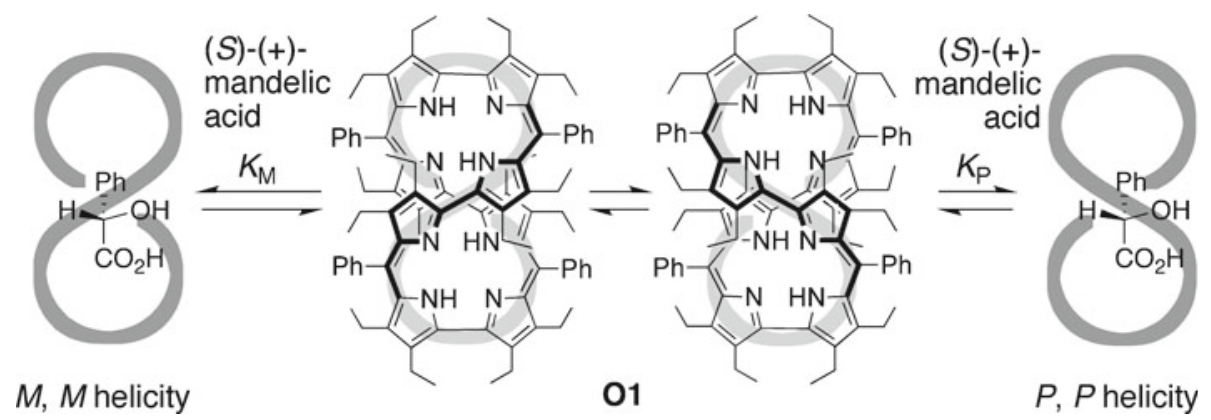

Scheme 6. Generation of diastereomeric excess of helical chirality with homochiral guest.

mononuclear and dinuclear complexes in $43 \%$ and $50 \%$ yield, respectively, and their figure-eight structures were characterized by X-ray crystallography (figure 3). ${ }^{22}$ The helical chirality of these metal complexes is fixed and therefore enantiomeric separation of the

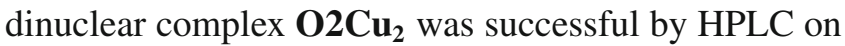
a chiral phase. The HPLC first fraction showed a positive $1^{\text {st }}$ Cotton effect at $697 \mathrm{~nm}$ and the second fraction showed a negative $1^{\text {st }}$ Cotton effect at the same wavelength (figure 4c). These CD spectral features are very similar to those of $\mathbf{O 2}$ complexed with $(R)-(-)$ - and $(S)-(+)$-mandelic acid, respectively (figure $4 \mathrm{a})$. Therefore, a particular helical form is favoured when $\mathbf{O 2}$ as well as $\mathbf{O 1}$ is complexed with homochiral carboxylic acids (scheme 7). TDDFT calculation of the UV-vis and $\mathrm{CD}$ spectra on the basis of the X-ray structure of $\mathrm{O2Cu}_{2}$ in the $M, M$ helicity satisfactorily reproduced the spectra of the HPLC second fraction. Therefore, the negative $1^{\text {st }}$ Cotton effect was associated with the $M, M$ helical form. This assignment is consistent with the prediction made by exciton chirality method that correlates the sign of the $1^{\text {st }}$ Cotton effect with the coupling dipole direction, clockwise or counterclockwise, of the electronic transition moments of the neighbouring two chromophores. Transition moment of the front bisdipyrrin chromophore in the figureeight screw of $(M, M)-\mathbf{O 2 C \mathbf { C u } _ { 2 }}$ couples with that in the backside bisdipyrrin chromophore through counterclockwise rotation and thus negative $1^{\text {st }}$ Cotton effect is predicted according to the exciton chirality method
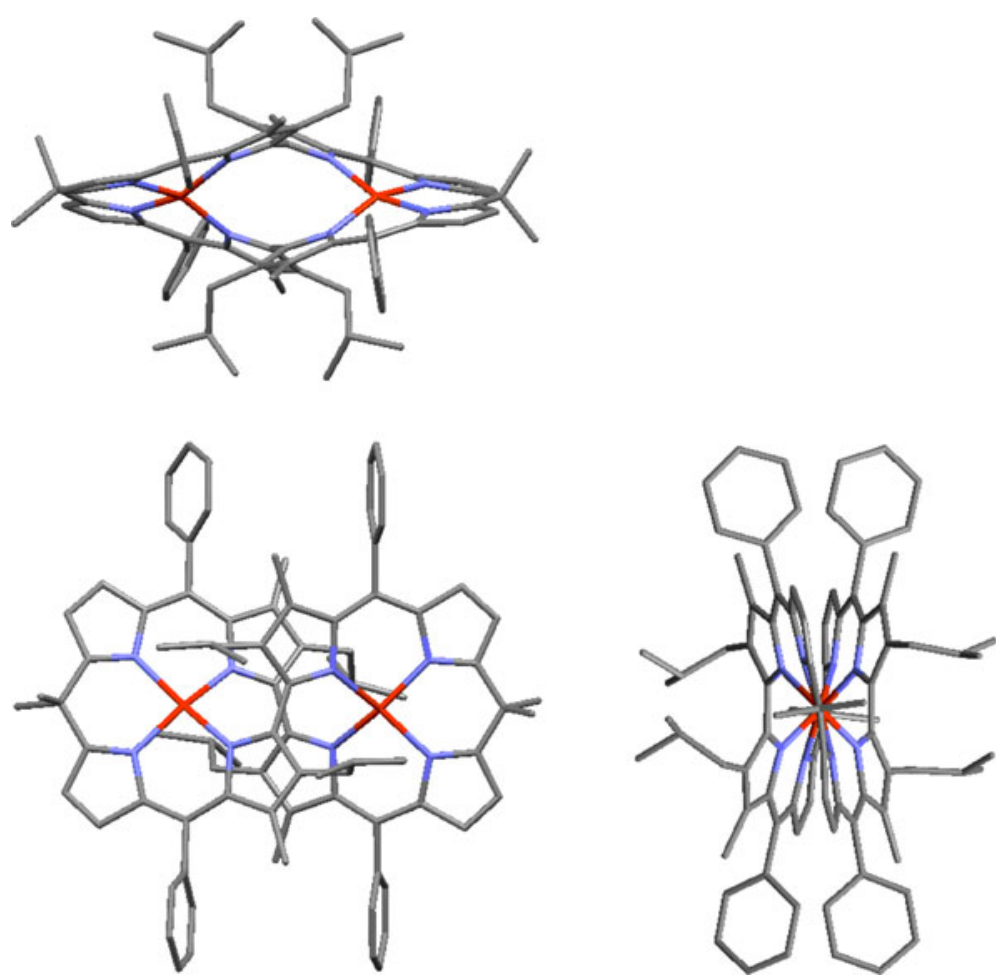

Figure 3. X-ray diagram of $\mathbf{O} 2 \mathbf{C u}_{2}$ viewed along right axes. 

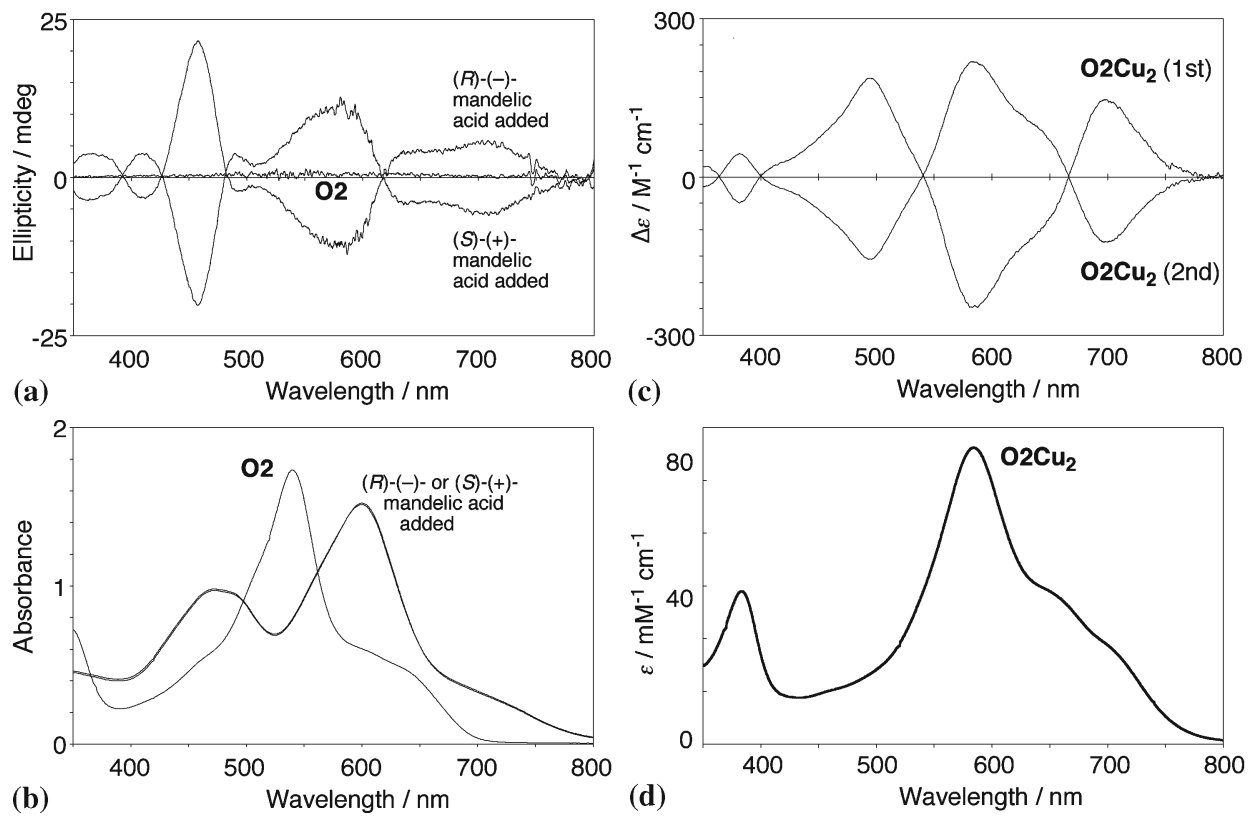

Figure 4. $\mathrm{CD}(\mathbf{a})$ and $\mathrm{UV}$-vis (b) spectral changes of $\mathbf{O} 2(18 \mu \mathrm{M})$ in $\mathrm{CH}_{2} \mathrm{Cl}_{2}(3 \mathrm{~mL})$ by adding $(S)-(+)$-mandelic acid or $(R)-(-)$-mandelic acid (200 molar equiv) in $\mathrm{MeOH}$ $(40 \mu \mathrm{L})$. CD (c) and UV-vis (d) spectra of the HPLC fractions of $\mathbf{O 2 C \mathbf { U } _ { 2 }}$ on a chiral phase.

(figure 5, left). ${ }^{23}$ Because of the closely related structure of $\mathrm{O1}$ and $\mathrm{O2}, M, M$ helicity induction is suggested for the $(S)-(+)$-mandelic acid complex of $\mathbf{O 1}$ that displays a negative $1^{\text {st }}$ Cotton effect (figure $2 a$ ).
When metallation reaction was done in the presence of chiral promoter such as $(R)-(+)-1-(1-$ phenyl)ethylamine, excess of $P, P$ helicity up to $19 \%$ ee resulted in the mononuclear $\mathbf{O 2 C u}$ complex $\left(k_{1 \mathrm{P}}>\right.$

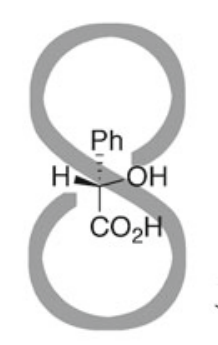

$P, P$ helicity

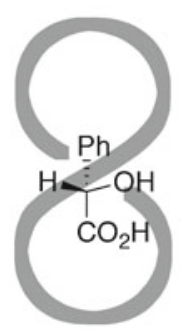

$M, M$ helicity

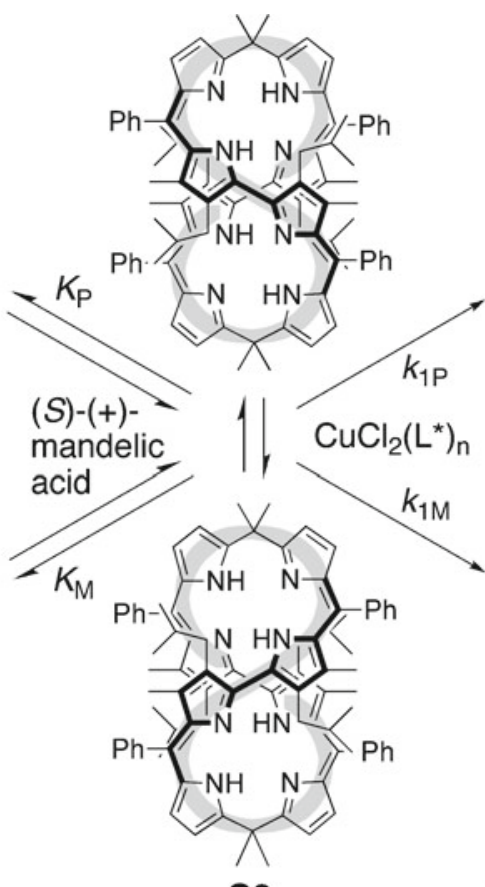

02

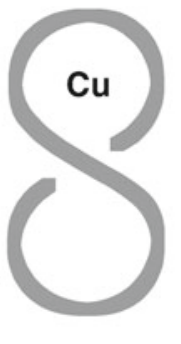

$\underset{k_{2 \mathrm{P}}}{\stackrel{\mathrm{CuCl}_{2}\left(\mathrm{~L}^{\star}\right)_{\mathrm{n}}}{\longrightarrow}}$

$\mathrm{Cu}$

$\stackrel{\mathrm{Cu}(\mathrm{OAc})_{2}}{\longrightarrow}$

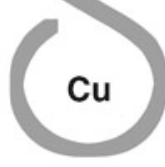

$(P, P)-02 \mathrm{Cu}$

$(P, P)-\mathrm{O} 2 \mathrm{Cu}_{2}$
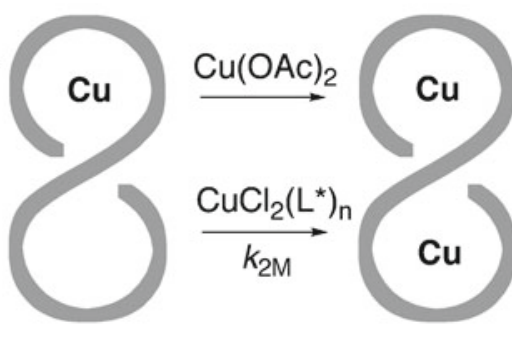

$(M, M)-\mathrm{O} C \mathrm{Cu}$

$(M, M)-02 \mathrm{Cu}_{2}$

Scheme 7. Generation of diastereomeric excess of helical chirality with homochiral guest and enantiomeric excess with homochiral promoter ( $\left.\mathrm{L}^{*}\right)$. Rate constants, $k_{1 \mathrm{M}}, k_{1 \mathrm{P}}$, $k_{2 \mathrm{M}}$, and $k_{2 \mathrm{P}}$, and equilibrium constants, $K_{\mathrm{M}}$ and $K_{\mathrm{P}}$, are shown. 

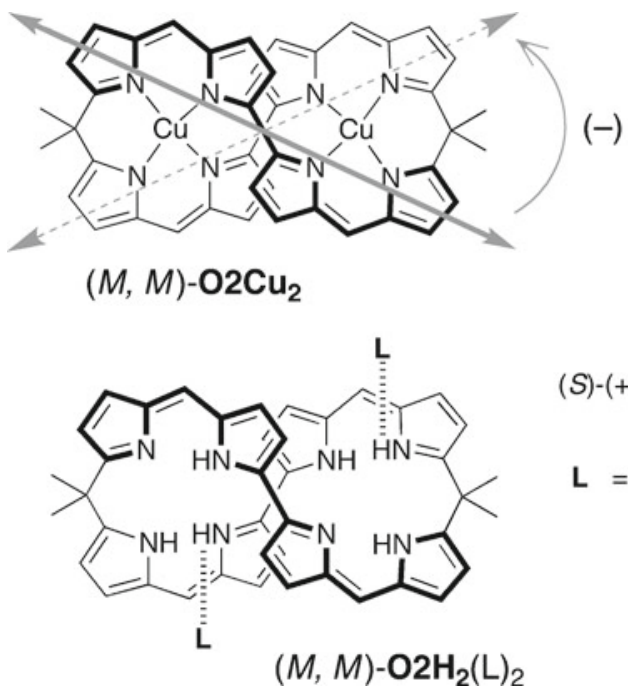

(S)-(+)-mandelate<smiles>O=C([O-])[C@H](O)c1ccccc1</smiles>

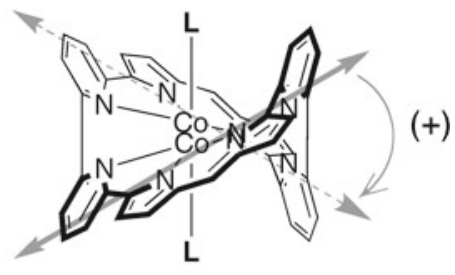

$(P, P)-\mathrm{O} \mathrm{Co}_{2}(\mathrm{~L})_{2}$

Figure 5. Coupling dipole direction of electronic transition moments of $(M, M)$ $\mathbf{O} 2 \mathbf{C u}_{2}$ (top, left) and $(S)$-mandelate complex of $(P, P)-\mathbf{O} 3 \mathbf{C o}_{2}(\mathbf{L})_{2}$ (top, right) with its side view (bottom, right). Predicted $M, M$ helicity of the $(S)$-mandelate complex of diprotonated $\mathbf{O 2}$ (bottom, left).

$\left.k_{1 \mathrm{M}}\right)$ if $800 / 400 / 1$ ratio of amine/Cu/O2 was used at $0{ }^{\circ} \mathrm{C}$. The enantiomeric excess $(\% e e)$ could be determined by the $\mathrm{CD}$ intensity after conversion of the product $\mathbf{O 2 C u}$ complex into $\mathbf{O} 2 \mathbf{C u}_{2}$. Furthermore, the same chiral amine accelerated the insertion of the second $\mathrm{Cu}$ ion to the $P, P$ form of $\mathbf{O 2 C u}\left(k_{2 \mathrm{P}}>k_{2 \mathrm{M}}\right){ }^{22}$ That is, when a racemic mixture of $\mathbf{O 2 C u}$ was treated with $(R)-(+)-1-(1$-phenyl)ethylamine (10 equiv) and $\mathrm{CuCl}_{2} \bullet 2 \mathrm{H}_{2} \mathrm{O}$ (5 equiv) in $\mathrm{CH}_{2} \mathrm{Cl}_{2}$, ee value of $33 \%$ was observed for $(P, P)-\mathbf{O 2} \mathbf{C u}_{2}$ in the initial stage of the metallation (table 2, entry 1), although this reaction condition does not make remarkable difference between the rate constants, $k_{1 \mathrm{M}}$ and $k_{1 \mathrm{P}}$, to result in only $2 \%$ $e e$ for $(P, P)-\mathbf{O 2 C u}$. This means that the rate $\left(k_{2 \mathrm{P}}\right)$ for the metal insertion into $(P, P)-\mathbf{O 2 C u}$ is twice as fast as the rate $\left(k_{2 \mathrm{M}}\right)$ for the metal insertion into $(M, M)$ $\mathbf{O 2 C u}$. As the metallation proceeds, $(P, P)-\mathbf{O 2 C u}$ is consumed faster, which is consistent with the development of excess of the $M, M$ helicity for $\mathbf{O 2 C u}$. Thus, $72 \%$ ee of $M, M$ helicity was observed for $\mathbf{O 2 C u}$ at the final stage of the metallation (table 2, entry 5). These results show that kinetic resolution may be a potential means in preparation of metal porphyrinoids with high optical purity.

\subsection{Dynamic helicity change in the metal porphyrinoids}

As described above, $\mathbf{O 1}$ and $\mathbf{O 2}$ can be induced to adopt a particular unidirectional helical conformation

Table 2. Conversion of racemic $\mathrm{O} 2 \mathrm{Cu}$ to $\mathbf{O} 2 \mathrm{Cu}_{2}$ by $\mathrm{CuCl}_{2} \bullet 2 \mathrm{H}_{2} \mathrm{O}$ in the presence of $(R)-(+)-1-(1-p h e n y l)$ ethylamine at room temperature in $\mathrm{CH}_{2} \mathrm{Cl}_{2}$. ${ }^{[a]}$

\begin{tabular}{|c|c|c|c|c|c|c|}
\hline Entry & Time (h) & $\begin{array}{c}\text { CD sign } \\
669 \mathrm{~nm} \\
\mathbf{O 2 C u}\end{array}$ & $\begin{array}{c}e e(\%)^{[\mathrm{b}]} \\
\mathbf{O 2 C u}\end{array}$ & $\begin{array}{l}\text { CD sign } \\
697 \mathrm{~nm} \\
\mathbf{O} 2 \mathbf{C u}_{2}\end{array}$ & $\begin{array}{l}e e(\%) \\
\mathbf{O} 2 \mathrm{Cu}_{2}\end{array}$ & 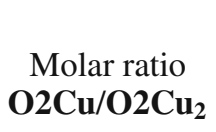 \\
\hline 1 & 3 & - & 3 & + & 33 & $9 / 1$ \\
\hline 2 & 9 & - & 15 & + & 29 & $6 / 4$ \\
\hline 3 & 12 & - & 25 & + & 25 & $5 / 5$ \\
\hline 4 & 16 & - & 36 & + & 19 & $3 / 7$ \\
\hline 5 & 24 & - & 72 & + & 6 & $1 / 9$ \\
\hline
\end{tabular}

[a] $\mathrm{CH}_{2} \mathrm{Cl}_{2}$ solution of $\mathbf{O 2 C u}(0.36 \mu \mathrm{M})$ was reacted with a molar ratio (amine/ $\mathrm{CuCl}_{2} \bullet 2 \mathrm{H}_{2} \mathrm{O} / \mathrm{O} 2$ ) $10 / 5 / 1$. [b] $\%$ ee was determined using $\left|\Delta \varepsilon_{583}-\Delta \varepsilon_{496}\right|$ as an index after conversion to $\mathbf{O 2} \mathbf{C u}_{2}$ by $\mathrm{Cu}(\mathrm{OAc})_{2} \bullet \mathrm{H}_{2} \mathrm{O}$, if necessary 
preferentially by complexation with homochiral carboxylic acids in $\mathrm{CH}_{2} \mathrm{Cl}_{2}$. Such complexes of homochiral carboxylic acids are labile and the $\mathrm{CD}$ response at around $600 \mathrm{~nm}$ has almost gone in $\mathrm{MeOH}$ even if cyclooctapyrrole retains its protonated form. This indicates that binding interaction supplied mainly by hydrogen bondings does not work well in protic media. Metal-ligand coordination bondings are generally much stronger than hydrogen bondings so that helical chirality of cyclooctapyrroles would find much wider application if homochiral ligand molecules coordinate reversibly to cyclooctapyrrole metal complexes. However, examples of porphyrinoid metal complexes having additional ligands are not only limited, but also well-defined substitution labile metal complexes of large porphyrinoids have never been known. ${ }^{24}$ Furthermore, although metal insertion is useful for the purpose of freezing transiently produced unidirectional helical chirality of cyclooctapyrrole free base as shown for $\mathbf{O} 2 \mathrm{Cu}_{2},{ }^{22,25}$ it becomes a serious problem if helical chirality change responding to the stereochemistry of the additional ligand is intended in the framework of cyclooctapyrrole metal complexes.

A hybrid macrocycle $\mathbf{O 3}$ composed of bipyridines and dipyrrins gave biscobalt complexes of figure-eight conformation with $k^{2}$-carboxylate ligands at the axial sites. ${ }^{18} \mathrm{X}$-ray crystallography of $\mathbf{O 3 C o}_{2}(\mathbf{O C O P h})_{2}$ shows that each hexadentate Co is ligated by dipyrrin nitrogens, a bipyridine nitrogen, $k^{2}$-benzoate oxygens, and a water oxygen (figure 6 ). The $2,2^{\prime}$-bipyridine units take an anti conformation where the $\mathrm{N}-\mathrm{C}-\mathrm{C}-\mathrm{N}$ torsion angles are 146.6 and $139.1^{\circ}$, leading to figure eight macrocycle conformation. Two carboxylate ligands are on the opposite sides of the macrocycle and close to the water ligand at the axial position of the neighbouring $\mathrm{Co}$ atom. One bipyridine unit is not coordinating to Co but their nitrogens are involved in the hydrogen bonding with the water ligands $(\mathrm{N}-\mathrm{O}$ distance: 2.791 and $2.870 \AA$ ). The Co-N(pyridine) bonds (2.358 and $2.367 \AA$ ) are much longer than the $\mathrm{Co}-\mathrm{N}$ (pyrrole) bonds $(1.965 \sim 2.121 \AA)$ and tilted from the pyridine plane $\left(27.7^{\circ}\right.$ and $\left.28.3^{\circ}\right)$. These structural feature causes reversible cleavage of the $\mathrm{Co}-\mathrm{N}$ (pyridine) bonding that would be crucial for the helicity change of the macrocycle. The axial acetate ligands of $\mathbf{O 3 C o}_{2}(\mathbf{O A c})_{2}$ are readily exchanged with carboxylates of $\alpha$-hydroxyl acids and $\alpha$-amino acids in water to cause helical chirality induction in $100 \%$ diastereoselectivity in some cases as evidenced by a CD couplet at $550 \mathrm{~nm}$. A typical couplet with a positive Cotton effect at $597 \mathrm{~nm}$ and a negative Cotton effect at $538 \mathrm{~nm}$ appeared during the CD titration of $\mathbf{O 3 C o}_{2}(\mathbf{O A c})_{2}(4.98 \mu \mathrm{M})$ in $\mathrm{CH}_{2} \mathrm{Cl}_{2}$ with a mixture of $(S)-(+)$-mandelic acid $(1.99 \mathrm{mM})$ and triethylamine $(2.40 \mathrm{mM})$ in $\mathrm{CH}_{2} \mathrm{Cl}_{2} / \mathrm{CH}_{3} \mathrm{CN}(19 / 1 \mathrm{v} / \mathrm{v})$ (figure 7). Saturation occurred at ca. 20-fold molar equiv of the carboxylate. The product complex was isolated and the NMR analysis demonstrated $88 \%$ diastereomeric excess (de). Because the UV-vis absorption band of these binuclear $\mathrm{Co}^{\mathrm{II}}$ complexes at $550 \mathrm{~nm}$ can be associated with the electronic transition of the

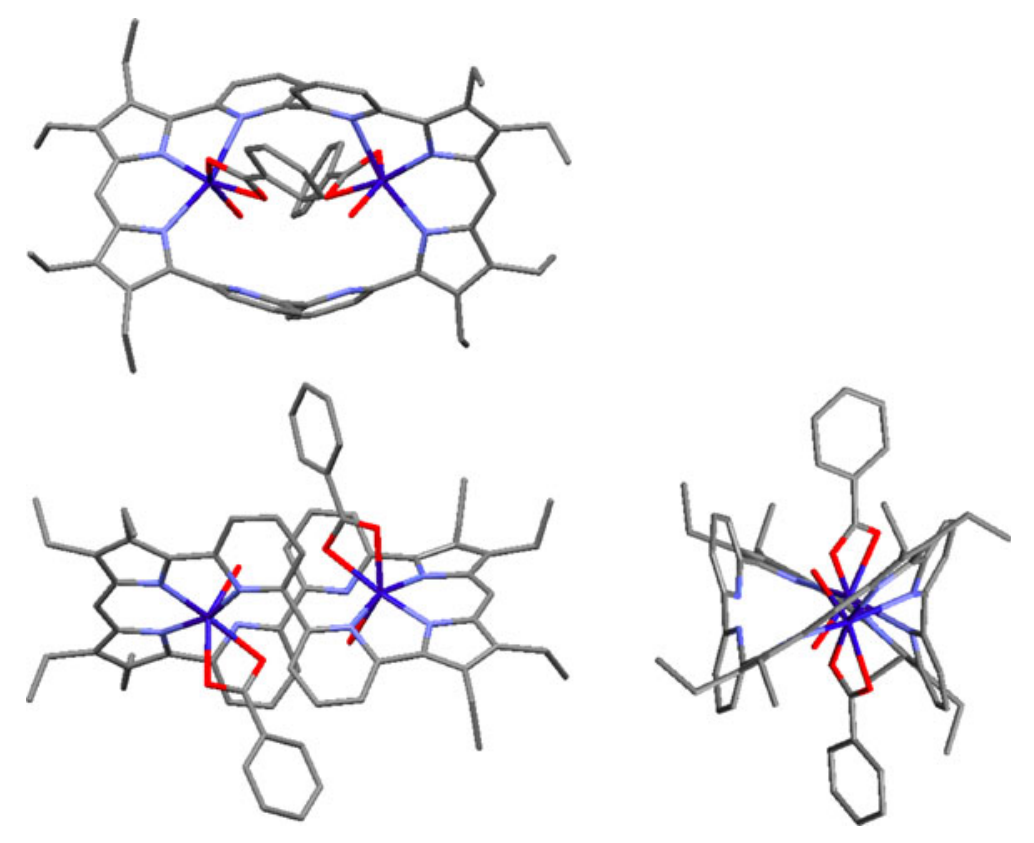

Figure 6. X-ray diagram of $\mathbf{O 3 C o}_{2}(\mathbf{O C O P h})_{2}$ viewed along right axes. 


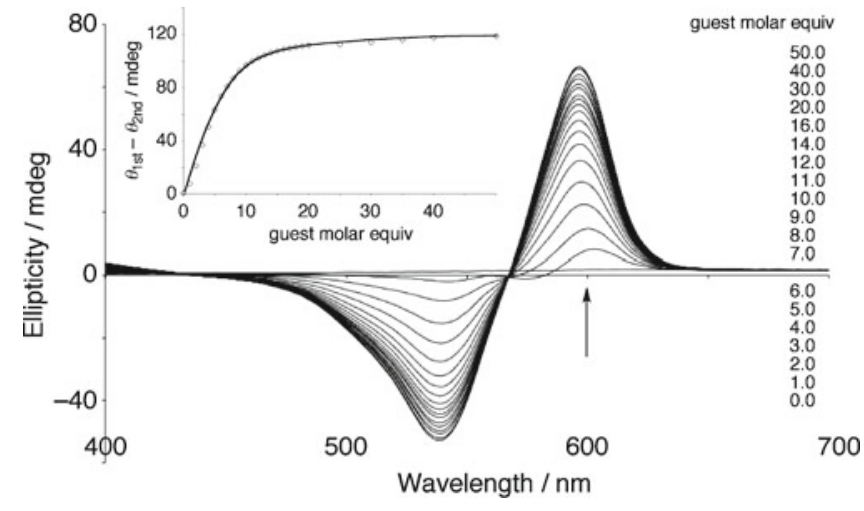

Figure 7. $\mathrm{CD}$ titration of $\mathbf{O 3 C o}_{2}(\mathbf{O A c})_{2}(4.98 \mu \mathrm{M})$ in $\mathrm{CH}_{2} \mathrm{Cl}_{2}$ with $(S)-(+)$-mandelic acid $(1.99 \mathrm{mM})$ and triethylamine $(2.40 \mathrm{mM})$ in $\mathrm{CH}_{2} \mathrm{Cl}_{2} / \mathrm{CH}_{3} \mathrm{CN}(19 / 1)$. Inset: A titration curve of the $\mathrm{CD}$ intensity vs. added molar equiv of the carboxylate.

dipyrrin chromophore, their exciton coupling should be responsible for the $\mathrm{CD}$ couplet at around $550 \mathrm{~nm}$. Thus, a positive couplet induced by $(S)-(+)$-mandelate means
$P, P$ helicity seen in the exciton coupling diagram in figure 5 (right) according to the exciton chirality method. ${ }^{23}$

The ligand exchange is so fast that anionic ligands can be extracted from water layer. When a two-phase mixture of $\mathbf{O 3 C o}_{2}(\mathbf{O A c})_{2}$ in $\mathrm{CH}_{2} \mathrm{Cl}_{2}$ and L-threonine (100-fold molar equiv) with $\mathrm{NaOH}$ (30-fold molar equiv) in water was stirred for $30 \mathrm{~min}$, the reaction was completed to give $\mathbf{O 3 C o}_{2}(\mathbf{T h r})_{2}$ in $77 \%$ isolated yield. The ${ }^{1} \mathrm{H}$ NMR spectrum showed that a single diastereomer was generated. In fact, L- and D-threonine generated mirror image $\mathrm{CD}$ spectra with the highest $\mathrm{CD}$ intensity among amino acids as seen in table 3 where the sign and wavelength of the $1^{\text {st }}$ Cotton effect with its $|\Delta \theta|$ value are listed for $19 \mathrm{~L}$-amino acids. This strict stereo control would be ascribed to two chiral centres present at the $\alpha$ - and $\beta$-carbon of threonine. The induced CD intensity is sensitive to the nature of amino acids. Amino acids of an aryl side chain (Phe, Tyr, Trp) induced strong CD intensity as much as Thr

Table 3. UV-vis and CD data of Co complexes ligated by amino acid anions. ${ }^{[a]}$

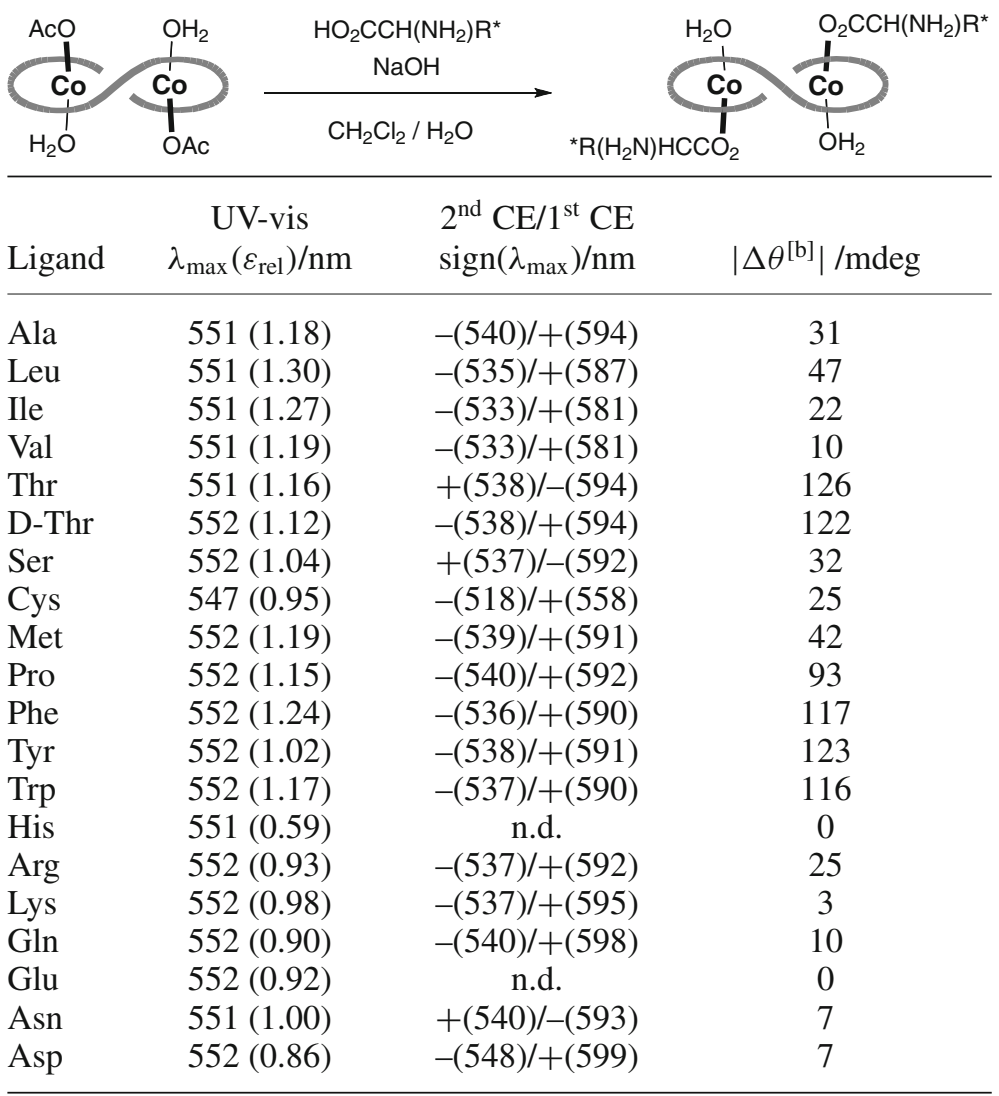

[a] Data were taken in $\mathrm{CH}_{2} \mathrm{Cl}_{2}$ containing $\mathbf{O 3 C \mathbf { C o } _ { 2 }}(\mathbf{O A c})_{2}(4.7 \mu \mathrm{M})$ after stirring for $30 \mathrm{~min}$ with aqueous solution of amino acids $(0.47 \mathrm{mM} ; 100$ fold molar equiv) and $\mathrm{NaOH}(0.14 \mathrm{mM}) .{ }^{[\mathrm{b}]}$ the $\mathrm{CD}$ intensity $|\Delta \theta|$ is the difference value between the $1^{\text {st }}$ Cotton and the 2 nd Cotton effect $\mid \theta_{1 \text { st }}$ $-\theta_{2 \text { nd }} \mid$. 

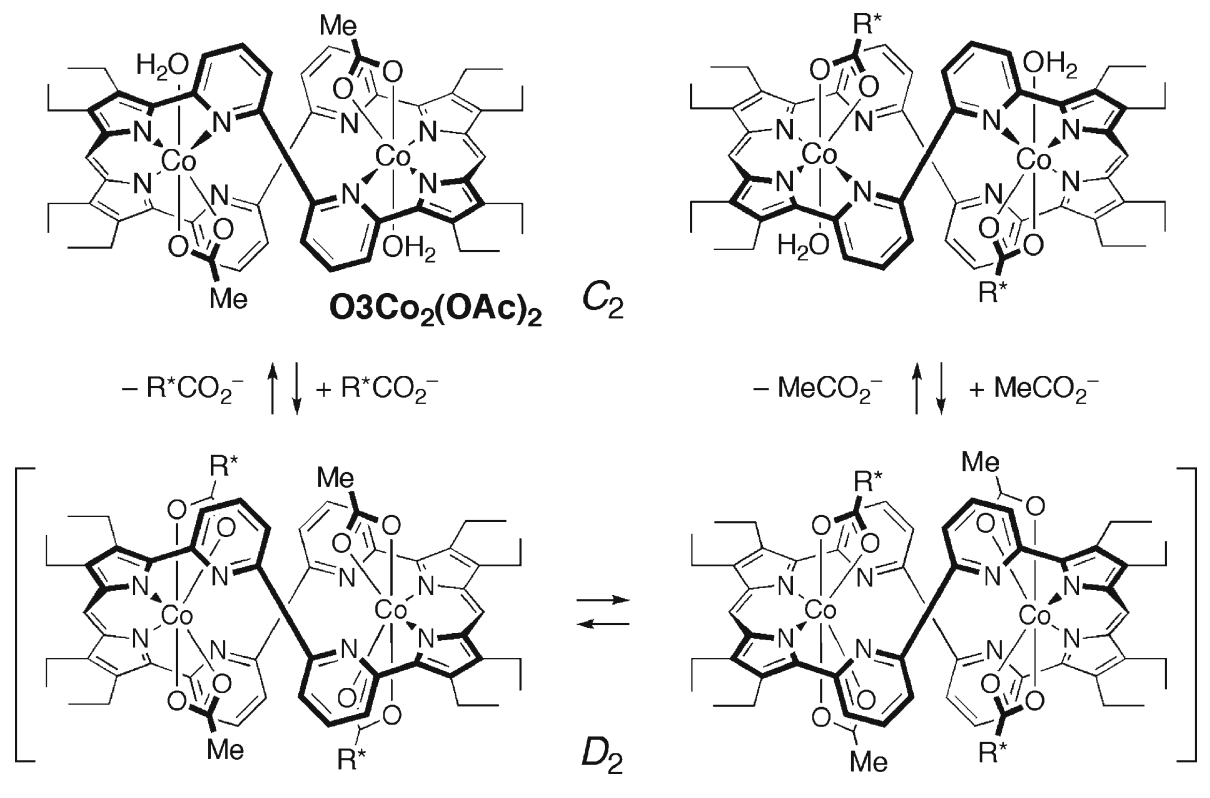

Scheme 8. Plausible ligand substitution pathway with helicity change.

to suggest very high stereo control. On the other hand, amino acids of an alkyl side chain usually showed weaker CD intensity. When amino acid's side chain contains strongly polar functionality, the $\mathrm{CD}$ induction is negligibly small. Since the size of $\mathrm{OH}, \mathrm{CH}_{3}$, and $\mathrm{NH}_{2}$ groups at the $\alpha$-carbon of carboxylates fits inside the crevice surrounded by the walls of pyridine rings, the bulkier substituent at the $\alpha$-carbon hits or circumvents those walls depending on the helical handedness of the macrocycle. This explains universal relationship between a positive $1^{\text {st }}$ Cotton effect at around $590 \mathrm{~nm}$ and the $(S)$-configuration at the $\alpha$-position of carboxylic acids. Thr, and Ser have a hydroxyl group at the $\beta$-carbon and Asn has an amide oxygen or nitrogen at the $\gamma$-carbon. If these remote functionalities favour the position inside macrocycle crevice to participate in the hydrogen bonding interaction with axial ligand sitting side by side at the next metal site, it would be responsible for their opposite CD sign.

As revealed by X-ray, the bipyridine nitrogens are anchored to Co directly through the weak coordination bonding and indirectly through the hydrogen bonding to the axial water ligands. It is reasonably assumed that the added carboxylate anions would replace the axial water ligands with concomitant cleavage of the weakly coordinating bipyridine nitrogens of the $C_{2}$-symmetric bis(aquo)bis ( $k^{2}$ carboxylato)bisCo complex to generate a $D_{2}$-symmetric intermediate of dual six-coordinate bis $\left(k^{2}\right.$-carboxylato)(dipyrrinato)Co coordination mode as depicted in scheme 8 . The bipyridine units of the latter are free to make helicity change of the macrocycle for a favoured helical screw.

\section{Conclusions}

The unique figure-eight conformation of cyclooctapyrroles is a potentially useful scaffold for developing molecular tools for chirality science. Properly designed expanded porphyrins for application to chirality induction and chirality sensing are described here. Binding chiral carboxylic acids to $\mathbf{O 1}$ through multiple hydrogen bondings is the basis for generating helical chirality that can be detected by $\mathrm{CD}$ response at visible region. Remarkable read-out accuracy of $\mathbf{O 1}$ for the absolute configuration of carboxylic acids was demonstrated. While those dynamic chirality transfer from carboxylate anions to protonated porphyrioids was weakened in protic media, helicity is memorized in the form of metal complexes. Study on the $\mathrm{Cu}$ complexes of $\mathbf{O 2}$ elucidated relationship between the sign of the $\mathrm{CD} 1^{\text {st }}$ Cotton effect and the helical handedness. Furthermore, enantiomeric excess of the $\mathrm{Cu}$ complex of $\mathbf{O 2}$ was induced by chiral promoter in the metallation process. Finally, Co complexes of $\mathbf{O 3}$ with carboxylate ligands were isolated to show that the chirality of the axial ligands has a great influence on the helical chirality of the macrocycle. These Co complexes underwent ligand exchange with concomitant helicity change that is enabled by reversible on-off coordination of the bipyridine nitrogens within the macrocycle. Such dynamic feature of the Co complex enabled to pick up amino acid anions in water and showed characteristic CD response depending on the amino acid. Structural design of expanded porphyrin analogues warrants further development of functional materials for chiral science. 


\section{References}

1. (a) Jasat A and Dolphin A 1997 Chem. Rev. 97 2267; (b) Sessler J L, Gebauer A and Weghorn S J 2000 in The porphyrin handbook, vol. 2, K M Kadish, K M Smith, R Guilard (eds) (San Diego: Academic Press) pp55; (c) Sessler J L and Seidel D 2003 Angew. Chem. Int. Ed. 42 5134; (d) Chandrashekar T K and Venkatraman S 2003 Acc. Chem. Res. 36 676; (e) Misra R and Chandrashekar T K 2008 Acc. Chem. Res. 41 265; (f) Stȩpień M, Sprutta N and Latos-Grażyński L 2011 Angew. Chem. Int. Ed. 504288

2. Sessler J L, Weghorn S J, Lynch V and Johnson M R 1994 Angew. Chem. Int. Ed. 331509

3. (a) Vogel E, Bröring M, Fink J, Rosen D, Schmickler H, Lex J, Chan K W K, Wu Y-D, Plattner D A, Nendel M and Houk K N 1995 Angew. Chem. Int. Ed. 34 2511; (b) Bröring M, Jendrny J, Zander L, Schmickler H, Lex J, Wu Y-D, Nendel M, Chen J, Plattner D A, Houk K N and Vogel E 1995 Angew. Chem. Int. Ed. 34 2515

4. (a) Jux N 2008 Angew. Chem. Int. Ed. 47 2; (b) Shin J-Y, Kim K S, Yoon M-C, Lim J M, Yoon Z S, Osuka A and Kim D 2010 Chem. Soc. Rev. 392751

5. Werner A, Michels M, Zander L, Lex J and Vogel E 1999 Angew. Chem. Int. Ed. 383650

6. Rzepa H S 2009 Org. Lett. 113088

7. (a) Berova N, Di Bari L and Pescitelli G 2007 Chem. Soc. Rev. 36 914; (b) Hembury G A, Borovkov V V and Inoue Y 2008 Chem. Rev. 108 1; (c) Mizuno Y and Aida T 2003 Chem. Commun. 20; (d) Kubo Y, Ohno T, Yamanaka J, Tokita S, Iida T and Ishimaru Y $2001 \mathrm{~J}$. Am. Chem. Soc. 123 12700; (e) Yagi S, Morinaga T, Nomura T, Takagishi T, Mizutani T, Kitagawa S and Ogoshi H 2001 J. Org. Chem. 663848

8. (a) Rosaria L, D'Urso A and Mammana A and Purrello R 2008 Chirality 20 411; (b) Mizuno Y, Aida T and Yamaguchi K 2000 J. Am. Chem. Soc. 122 5278; (c) Sugasaki A, Ikeda M, Takeuchi M, Robertson A and Shinkai S 1999 J. Chem. Soc., Perkin Trans. 13259

9. Rothemund P 1936 J. Am. Chem. Soc. 58625

10. Arsenault G P, Bullock E and MacDonald S F 1960 J. Am. Chem. Soc. 824384

11. (a) Lindsey J S 2000 in The porphyrin handbook, vol. 1, K M Kadish, K M Smith and R Guilard (eds) (New York:
Academic Press) pp45; (b) Laha J K, Dhanalekshmi S, Taniguchi M, Ambroise A and Lindsey J S 2003 Org. Process Res. Dev. 7799

12. Setsune J, Tanabe A, Watanabe J and Maeda S 2006 Org. Biomol. Chem. 42247

13. Setsune J and Maeda S 2000 J. Am. Chem. Soc. 122 12405

14. (a) Sessler J L, Weghorn S J, Morishima T, Rosingana M, Lynch V and Lee V 1992 J. Am. Chem. Soc. 114 8306; (b) Setsune J, Katakami Y and Iizuna N 1999 J. Am. Chem. Soc. 1218957

15. Setsune J, Tsukajima A and Watanabe J 2006 Tetrahedron Lett. 471817

16. (a) Barton D H R and Zard S Z 1985 J. Chem. Soc. Chem. Commun. 1098; (b) Sessler J L, Mozaffari A and Johnson M R 1992 Org. Synth. 7068

17. Setsune J, Toda M, Watanabe K, Panda P K and Yoshida T 2006 Tetrahedron Lett. 477541

18. Setsune J, Kawama M and Nishinaka T 2011 Tetrahedron Lett. 521773

19. Mori M, Okawa T, Iizuna N, Nakayama K, Lintuluoto J M and Setsune J 2009 J. Org. Chem. 743579

20. Lintuluoto J M, Nakayama K and Setsune J 2006 Chem. Commun. 3492

21. (a) Mizutani T, Yagi S, Honmaru A, Murakami S, Furusyo M, Takagishi T and Ogoshi H 1998 J. Org. Chem. 63 8769; (b) Al-Sheikh Ali A, Benson R E, Blumentritt S, Cameron T S, Linden A, Wolstenholme D and Thompson A 2007 J. Org. Chem. 724947

22. Setsune J, Tsukajima A, Okazaki N, Lintuluoto J M and Lintuluoto M 2009 Angew. Chem. Int. Ed. 48771

23. (a) Hatano M 1986 Induced circular dichroism in biopolymer-dye systems (Berlin: Springer-Verlag); (b) Harada N and Nakanishi K 1983 Circular dichroic spectroscopy (New York: University Science Books)

24. (a) Arnold P L, Patel1 D, Wilson C and Love J B 2008 Nature 451 315; (b) Mori S and Osuka A 2008 Inorg. Chem. 47 3937; (c) Cuesta L, Tomat E, Lynch V M and Sessler J L 2008 Chem. Commun. 3744; (d) Sessler J L, Tomat E, Mody T D, Lynch V M, Veauthier J M, Mirsaidov U and Markert J T 2005 Inorg. Chem. 44 2125

25. (a) Mori, M and Setsune J 2007 Chem. Lett. 36 244; (b) Setsune J, Mori M, Okawa T, Maeda S and Lintuluoto J M 2007 J. Organometal. Chem. 692166 